\title{
Microcontroller-Based Seat Occupancy Detection and Classification ${ }^{+}$
}

\author{
Ernesto Sifuentes ${ }^{1}$, Rafael González-Landaeta ${ }^{1}$, Juan Cota-Ruiz ${ }^{1}$ and Ferran Reverter ${ }^{2, *}$ \\ 1 Department of Computer and Electrical Engineering, Universidad Autónoma de Ciudad Juárez (UACJ), \\ Ciudad Juárez 32310, Mexico; esifuent@uacj.mx (E.S.); rafael.gonzalez@uacj.mx (R.G.-L.); \\ jcota@uacj.mx (J.C.-R.) \\ 2 Department of Electronic Engineering, Universitat Politècnica de Catalunya-BarcelonaTech, \\ 08860 Castelldefels, Spain \\ * Correspondence: ferran.reverter@upc.edu; Tel.: +34-934-137-076 \\ + Presented at the Eurosensors 2018 Conference, Graz, Austria, 9-12 September 2018.
}

Published: 13 November 2018

\begin{abstract}
This paper presents a microcontroller-based measurement system to detect and confirm the presence of a subject in a chair. The system relies on a single Force Sensing Resistor (FSR), which may be arranged in the seat or backrest of the chair, that undergoes a sudden resistance change when a subject/object is seated/placed over the chair. In order to distinguish between a subject and an inanimate object, the system also monitors small-signal variations of the FSR resistance caused by respiration. These resistance variations are then directly measured by a low-cost general-purpose microcontroller without using either an analogue processing stage or an analogue-to-digital converter, thus resulting in a low-cost, low-power, compact design solution.
\end{abstract}

Keywords: autonomous sensor; force sensing resistor; microcontroller; resistive sensor; seat occupancy detection; sensor interface electronics

\section{Introduction}

Seat-occupancy monitoring systems generally use mechanical sensors that detect weight, pressure, force or acceleration over the seat. These mechanical sensors can be resistive [1], capacitive [2] or inductive [3], but the former are the most common. Different types of resistive mechanical sensors can be employed, for instance: metallic strain gauges, semiconductor strain gauges and FSR, the latter being the cheapest and the most easily integrated into the chair structure. Mechanical sensors, however, have difficulties in distinguishing between subjects and objects seated/placed over the seat. This is usually solved by comparing the set of data to known patterns [4] or by combining the information of different types of sensor [5,6]; note that the capacitive sensor proposed in [6] does not rely on any mechanical measurement, but on the shielding effect generated by the human proximity. On the other hand, in health telemonitoring applications, resistive mechanical sensors have also been proposed to monitor the sitting posture [7] and the respiratory signal $[8,9]$ in wheelchairs and in conventional chairs.

This work proposes a novel measurement method for seat occupancy detection and classification using a single FSR. The additional information usually required in mechanical sensors for the subject-object classification is extracted from the FSR itself, by exploiting it to monitor the respiratory signal. The occupancy itself causes a large-signal variation of the FSR, whereas the respiration generates a small-signal variation that enables us to confirm the presence of a subject rather than an object. Both large- and small-signal variations of the FSR are then directly measured by a low-cost microcontroller using the concept of direct interface circuit (DIC) [10]. These have been 
extensively analyzed for resistive [11-14], capacitive [15] and inductive [16] sensors with different topologies, but not for resistive sensors undergoing both large- and small-signal variations.

\section{Operating Principle}

The proposed method relies on a single FSR, which is a sensor whose resistance $\left(R_{x}\right)$ decreases with increasing the force applied to it. This is a very low-cost and thin-size sensor with some limitations (e.g., low accuracy, non-linear response, and low interchangeability), but these are not critical here since the aim is to monitor variations, and not to determine the subject/object weight nor the respiratory rate.

According to Figure 1, three scenarios are possible: (1) The seat is vacant: $R_{x}$ remains constant to $R_{x, 0}$, which is the nominal resistance in zero-force conditions. (2) A subject is seated over the chair: $R x$ suddenly decreases (e.g., from $R_{x, 0}$ to $R_{x, 1}$ ) due to the subject's weight and then, as the subject stays there, his/her respiration causes small-signal variations of $R_{x}$ [ $\Delta R_{x}$ in Figure 1a] that enables us to confirm the presence of a subject. (3) An inanimate object is placed over the chair: $R_{x}$ undergoes a sudden decrease due to the object's weight but remains constant at $R_{x, 2}$, as shown in Figure $1 \mathrm{~b}$.

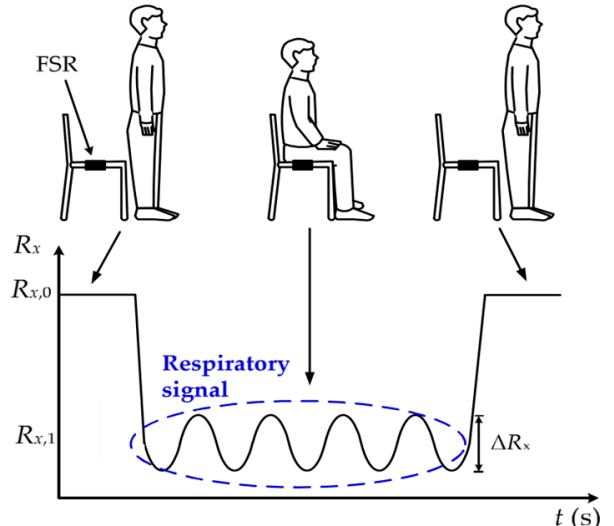

(a)

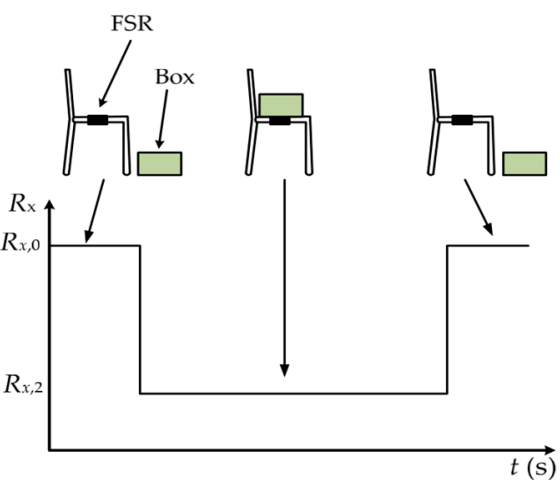

(b)

Figure 1. FSR variations when over the chair we have: (a) a subject; (b) an object.

The FSR, with a resistor $\left(R_{\mathrm{p}}\right)$ in parallel so as to linearize its response and also to avoid long measurements in zero-force conditions, is proposed to be monitored through a DIC [10], as shown in Figure 2a. Initially, Pin 1 provides a digital ' 1 ' and Pin 2 is in high-impedance (HZ) state and, consequently, the well-known capacitor $C$ is quickly charged to the supply voltage $\left(V_{\mathrm{DD}}\right)$. Next, Pin 1 is in $\mathrm{HZ}$ and Pin 2 provides a digital ' 0 ' so that $C$ is discharged towards ground through the equivalent resistance $\left(R_{\mathrm{eq}}=R_{\mathrm{p}} \| R_{x}\right)$ while an embedded timer measures the time interval required to do so. When the exponential discharging voltage crosses the threshold voltage $\left(V_{\mathrm{T}}\right)$ of the digital buffer embedded into Pin 1, the timer is read, as shown in Figure $2 \mathrm{~b}$. The resulting digital number is proportional to the discharging time $\left(T_{\mathrm{d}}\right)$ and also to $R_{\mathrm{eq}}$, since $T_{\mathrm{d}}=R_{\mathrm{eq}} \cdot C \cdot \ln \left(V_{\mathrm{DD}} / V_{\mathrm{T}}\right)$; this equation will be employed later to estimate $R_{\mathrm{eq}}$ from $T_{\mathrm{d}}$.

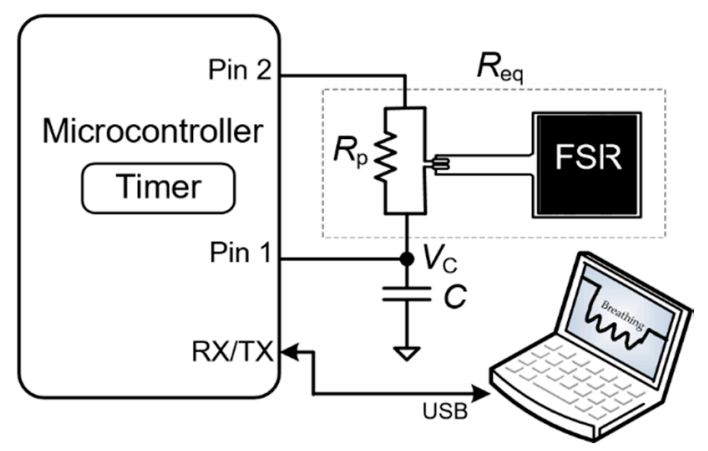

(a)

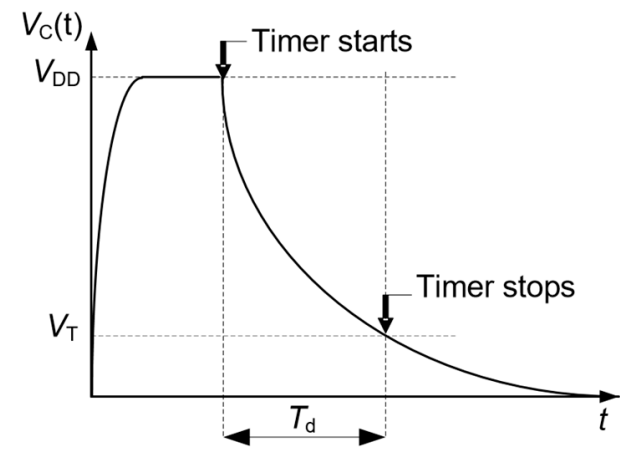

(b)

Figure 2. (a) DIC applied to measure the FSR; (b) waveform of the voltage across $C$. 


\section{Materials and Methods}

A commercial FSR (FSR 406 from Interlink Electronics) with $R_{x, 0}>10 \mathrm{M} \Omega$ and an active area of 4 $\times 4 \mathrm{~cm}^{2}$ was arranged in the seat of a chair. This FSR was connected to a DIC implemented by a lowcost low-power microcontroller (MSP430F123 from Texas Instruments, Dallas, TX, USA) with $V_{\mathrm{DD}}=$ 3.3 V. An embedded 16-bit timer running at $8 \mathrm{MHz}$ measured $T_{\mathrm{d}}$, which had information about the force applied to the FSR. Each measurement of $T_{\mathrm{d}}$ was transmitted via USB in real time to a personal computer and, then, converted to the corresponding value of $R_{\mathrm{eq}}$ through a control program implemented in LabVIEW ${ }^{\mathrm{TM}}$. We also selected $R_{\mathrm{p}}=3570 \Omega$ and $C=2.2 \mu \mathrm{F}$, which provide $T_{\mathrm{d}} \leq 8 \mathrm{~ms}$ thus avoiding the overflow of the timer. Although the length of $T_{\mathrm{d}}$ depended on the sensor resistance [17], the overall length of a single measurement (including the charge-discharge process, transmission and processing of the data) was controlled by LabVIEW ${ }^{\mathrm{TM}}$ and set to around $17 \mathrm{~ms}$. Accordingly, the sampling frequency was around $60 \mathrm{Sa} / \mathrm{s}$, which is sufficient enough to monitoring the respiration of a subject.

The system was experimentally tested with three healthy subjects of different weight and age (S1: $45 \mathrm{~kg} / 14$ years; S2: $64 \mathrm{~kg} / 39$ years; S3: $91 \mathrm{~kg} / 41$ years), and also with three objects of different weight $(\mathrm{O} 1: 5 \mathrm{~kg}$; O2: $10 \mathrm{~kg}$; $\mathrm{O} 3: 30 \mathrm{~kg})$. The volunteers were asked to seat over the chair and breathe freely, but to keep quiet during the measurement so as to avoid movement artifacts.

\section{Experimental Results}

The experimental results involving subjects and objects are shown in Figure 3a,b, respectively. According to Figure $3 \mathrm{a}$, when a subject sat down over the seat (at $t \approx 10 \mathrm{~s}$ ), a large-signal variation (between 600 and $2400 \Omega$ ) was observed, and this depended on the subject's weight. For the heaviest subject (S3), the resistance dropped to an average value of about $1250 \Omega$. While seated, small-signal resistance variations of around $\pm 150 \Omega$ with a respiratory rate between 12 (for S3) and 24 (for S1) breaths per minute, which correspond to a frequency between 0.2 and $0.4 \mathrm{~Hz}$, were monitored. This well-defined respiratory signal enables us to clearly confirm the presence of a subject over the chair without incorporating any other sensor. If the respiratory signal was contaminated by movement artifacts, the detection of the latter could also be employed as an indication of the presence of a subject over the seat.

Figure $3 b$, however, only shows the large-signal variation due to the object's weight, but not the small-signal variations as it was observed before with the subjects. It is worth mentioning that in Figure $3 \mathrm{~b}$ the large-signal variation is similar and even higher than in Figure 3a although the weight is lower. This is because the objects under test had small dimensions and, consequently, their weight caused a "point" force on the FSR that was higher than the corresponding component of distributed force generated by the subject.

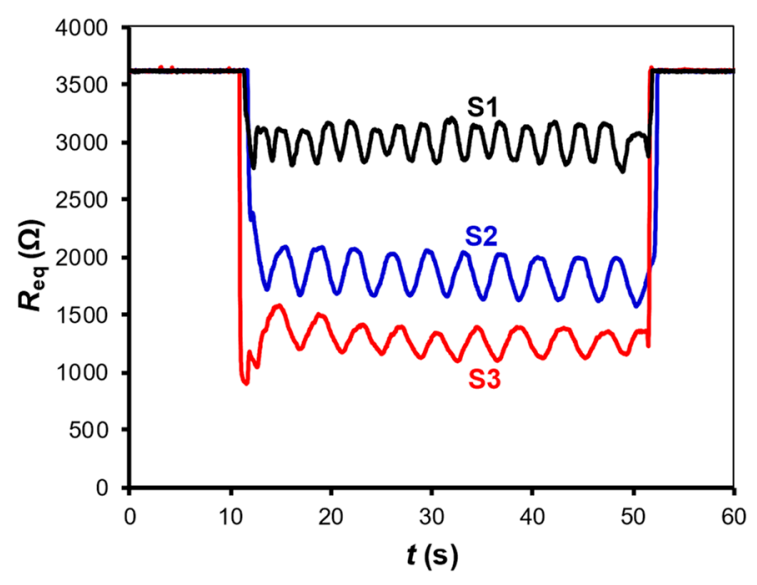

(a)

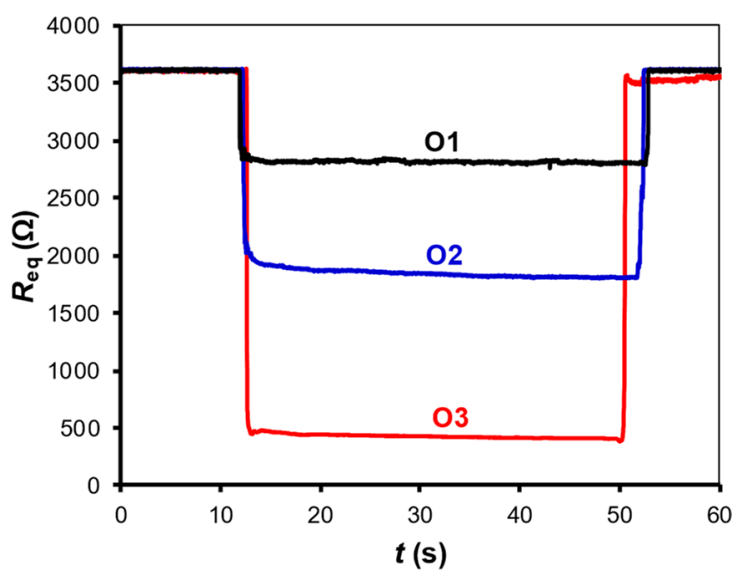

(b)

Figure 3. Experimental resistance variations monitored by the DIC shown in Figure 2 when over the chair we had: (a) subjects of different weight and age; (b) objects of different weight. 


\section{Conclusions}

This work has proved that detecting and confirming the presence of a subject in a chair is feasible using a single FSR directly connected to a general-purpose microcontroller. The proposed system first detects the subject by monitoring his/her weight and then confirms his/her presence by monitoring the respiration. We believe the proposed system is suitable for applications related to autonomous sensors where it is important to detect and confirm the presence of people sitting in chairs, such as intelligent airbag deployment systems and aircraft boarding systems.

Acknowledgments: Ernesto Sifuentes, Rafael González-Landaeta and Juan Cota-Ruiz have been funded by PRODEP and UACJ, México. The work of Ferran Reverter was supported by the Spanish Ministry of Economy and Competitiveness and the European Regional Development Fund under project TEC2016-76991-P.

Conflicts of Interest: The authors declare no conflict of interest. The founding sponsors had no role in the design of the study; in the collection, analyses, or interpretation of data; in the writing of the manuscript, and in the decision to publish the results.

\section{References}

1. Oestreicher, R.; Homann, M.; Lichtinger, H.; Morell, S.; Reich, D. Method and System for Determining Weight and Position of a Vehicle Seat Occupant. U.S. Patent 7082360, 25 July 2006.

2. Böse, H.; Fuß, E.; Ehrlich, J. Capacitive sensor mats for pressure detection with high sensitivity. In Proceedings of the Sensor and Measurement Technology 2015, Nürnberg, Germany, 19-21 May 2015; pp. 55-60.

3. Kisic, M.G.; Blaz, N.V.; Babkovic, K.B.; Zivanov, L.D.; Damnjanovic, M.S. Detection of seat occupancy using a wireless inductive sensor. IEEE Trans. Magn. 2017, 53, 1-4.

4. Breed, D.S.; DuVall, W.E.; Johnson, W.C. Dynamic Weight Sensing and Classification of Vehicular Occupants. U.S. Patent 7620521, 17 November 2009.

5. Pallàs-Areny, R.; Casas-Piedrafita, J.O.; Gasulla-Forner, M.; Aliau-Bonet, C.; Gaitan-Pitre, J. Method and Apparatus for the Continuous Detection of Seat Occupancy through the Combined Use of Weight, Capacitive and Thermal Sensors. WO Patent 2011104399, 1 September 2011.

6. George, B.; Zangl, H.; Bretterklieber, T.; Brasseur, G. A combined inductive-capacitive proximity sensor for seat occupancy detection. IEEE Trans. Instrum. Meas. 2010, 59, 1463-1470.

7. Roh, J.; Park, H.; Lee, K.J.; Hyeong, J.; Kim, S.; Lee, B. Sitting posture monitoring system based on a lowcost load cell using machine learning. Sensors 2018, 18, 208, doi:10.3390/s18010208.

8. Pino, E.J.; Arias, D.E.; Aqueveque, P.; Vilugrón, L.; Hermosilla, D.; Curtis, D.W. Monitoring technology for wheelchair users with advanced multiple sclerosis. In Proceedings of the IEEE Engineering in Medicine and Biology Society, Osaka, Japan, 3-7 July 2013; pp. 961-964.

9. Griffiths, E.; Scott, T.; Bernheim, A.J. Health chair: Implicitly sensing heart and respiratory rate. In Proceedings of the ACM Conference on Ubiquitous Computing, Seatle, WA, USA, 13-17 September 2014; pp. 661-671.

10. Reverter, F. The art of directly interfacing sensors to microcontrollers. J. Low Power Electron. Appl. 2012, 2, $265-281$.

11. Reverter, F.; Jordana, J.; Gasulla, M.; Pallàs-Areny, R. Accuracy and resolution of direct resistive sensor-tomicrocontroller interfaces. Sens. Actuators A Phys. 2005, 121, 78-87.

12. Reverter, F.; Casas, O. Interfacing differential resistive sensors to microcontrollers: A direct approach. IEEE Trans. Instrum. Meas. 2009, 58, 3405-3410.

13. Sifuentes, E.; Casas, O.; Reverter, F.; Pallas-Areny, R. Direct interface circuit to linearise resistive sensor bridges. Sens. Actuators A Phys. 2008, 147, 210-215.

14. Reverter, F.; Horak, G.; Bilas, V.; Gasulla, M. Novel and low-cost temperature compensation technique for piezoresistive pressure sensors. In Proceedings of the XIX IMEKO World Congress, Lisbon, Portugal, 6-11 September 2009; pp. 2084-2087.

15. Reverter, F.; Casas, O. Direct interface circuit for capacitive humidity sensors. Sens. Actuators A Phys. 2008, $143,315-322$. 
16. Kokolanski, Z.; Jordana, J.; Gasulla, M.; Dimcev, V.; Reverter, F. Direct inductive sensor-to-microcontroller interface circuit. Sens. Actuators A Phys. 2015, 224, 185-191.

17. Sifuentes, E.; Gonzalez-Landaeta, R.; Cota-Ruiz, J.; Reverter, F. Measuring dynamic signals with direct sensor-to-microcontroller interfaces applied to a magnetoresistive sensor. Sensors 2017, 17, 1150, doi:10.3390/s17051150.

(C) 2018 by the authors; Licensee MDPI, Basel, Switzerland. This article is an open access article distributed under the terms and conditions of the Creative Commons Attribution (CC BY) license (http://creativecommons.org/licenses/by/4.0/). 